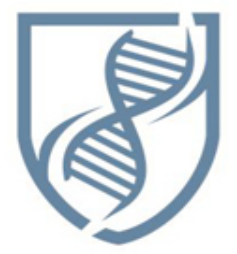

Journal of Bioscience and Applied Research

\section{JBAAR}

WWW.JBAAR.ORG

\title{
The protective effect of Coriandrum sativum L. oil against liver toxicity induced by Ibuprofen in rats
}

\author{
Hoda H. Baghdadi ${ }^{1}$,Fatma M.El-Demerdash ${ }^{2}$,Eman H. Radwan ${ }^{3}$, Sodfa Hussein ${ }^{4}$ \\ ${ }^{1,2,4}$ Department of Environmental Studies, Institute of Graduate Studies and Research, Alexandria University. \\ ${ }^{3}$ Zoology Department, Faculty of Science, Damanhour University. \\ (Corresponding author Email: dr_eman_hashem@yahoo.com)
}

\begin{abstract}
Ibuprofen (IBU) is a Non-steroidal anti-inflammatory drugused in the treatment of pain, fever and in inflammation.Coriandrum sativum is cultivated for its aromatic and medicinal uses. The present study aims to evaluatethe protective effect of Coriandrum sativum volatile oil on hepatotoxicityof IBU in rats. Five groups of albino rats were used.Group l(control),groupll (C.sativum oil,40 mg/kg B.W. for 14 day), group $1 \mathrm{ll}$ (IBU group, $100 \mathrm{mg} / \mathrm{kg}$ bodyweight B.W., for 14 day), group IV (IBU+ C.sativum oil) and groupV (recovery group).The activity of alanine aminotransferase (ALT) and aspartate aminotransferase (AST) were measured in the liver of different groups addition to the histological examination of the sections of liver. The results showed that IBU caused a significant decrease in the activity of ALT and AST in the liver. The histological examination of the liver showed many pathological changes. Administration of coriander volatile oilin the combination with IBU was able to significantly increase the activity of both AST and ALT, in the liver and caused a significant decrease in the deleterious effect induced by IBU. The present results confirm that the antioxidant activity of volatile oil of the Coriandrum sativum L., against hepatotoxicity of IBU.
\end{abstract}

Keywords: Ibuprofen, liver, Coriandrum sativum, Histopathology, Transaminases

\section{Introduction}

Ibuprofen (IBU) is used mostly for the inflammatory diseases such as rheumatoid arthritis, menstrual cramps, toothache, and dysmenorrhea (Chen et al., 2005; Mahalakshmiet al., 2010). Ibuprofen has the same action as that of aspirin and shares the same side effects to a lesser extent (Thangapandian, 2012).IBU has been used through different traditions and considered to have cooling, stimulant,carminative, digestive properties, cystitis (Aboelsoud, 2010), headaches, measles, rectal prolapse, preventcancer (Li and Ben, 1999), relief of anxiety and insomnia, and may have potential sedative, hypotensive, andmuscle relaxant effects (Emamghoreishi et al., 2005),diuretic, antipyretic,stomachic, aphrodisiac, laxative and anthelmintic properties (Deepa and Anuradha, 2011).On the other hand,Ibuprofen was commonly known to produce hepatotoxicity, inducing cholestatic hepatitis (Manov et al., 2006). Besides, ibuprofen was also found to be most active in impairing gluconeogenesis from lactate, and in impairing albumin synthesis in vitro (Castell et al., 1988).Lower dose of ibuprofen also induces more histopathological lesions in rats' liver than chlorpromazine, paracetamol and other (Schoonen et al., 2007). Various theories have been proposed for the mechanism by which ibuprofen damages the liver (Teoh and Farrell, 2003). It was reported to cause changes in the architecture of the hepatic cell, cell permeability and to create ionic imbalance resulting in increased intracellular calcium concentration. Consequently, mitochondrial activity was inhibited, leading to the death of hepatic cells (Saraf et al., 1994).

Plants, including herbs and spices, have many phytochemicals which are the potential source of natural antioxidant, e.g.; flavonoids, alkaloids, tannins and phenolic acids. Natural antioxidants are known to protect cells from damage induced by oxidative stress, which is generally considered to be a cause of aging, degenerative diseases, and cancer (Ringman et al., 2005).The health promoting effects of antioxidants from plants and spices are thought to arise from their protective effects by counteracting reactive oxygen species. Coriander 
(Coriandrumsativum L.) is of economic importance since it has been used as a flavoring agent in food products and drugs. This medicinal plant widely distributed and mainly cultivated for the seeds which contain an essential oil (ranges between 0.3\% and 1.1\%) (Neffati et al., 2011).The essential oil and various extracts from coriander have been shown to possess antibacterial, antidiabetic, anticancerous, antimutagenic, antioxidant and free radical scavenging activities (Zoubiri and Baaliouamer, 2010). Coriander is known for its wide range of healing properties. It is generally used in gastrointestinal complaints such as anorexia, dyspepsia, flatulence, diarrhea, griping pain and vomiting. Coriander fruit is also reputed as refrigerant, tonic, diuretic and aphrodisiac, while, the oil is considered useful in flatulent colic, rheumatism, and neuralgia. Coriander is used as antiedemic, anti-inflammatory, antiseptic,antihypertensive, lipolytic and myorelaxant, and possesses nerve-soothing property (Darughe et al., 2012). Coriander has also been reported to exhibit several pharmacological effects such anti-mutagenic activity, cholesterol lowering activity, hepatoprotective activity and in detoxification (Momin et al., 2012). The present study aims to evaluate the protective effect of Coriandrum sativum volatile oil on ibuprofen induced hepatotoxicity in rats.

\section{Materials and Methods Isolation of volatile oil of C.sativum:}

Coriandrum sativum $L$. is a small size fruit, was purchased from the local markets and the specimens were further authenticated in the herbarium of the Faculty of Science, Alexandria University, Egypt.A Clevenger-type apparatus was used for essential oil extraction. The essential oil was isolated from the full dried coriander fruits. About $100 \mathrm{gm}$ seeds for each treatment were set in a round bottom flask with distilled water $(1000 \mathrm{ml})$, enough to cover the coriander fruits. The process of hydro distillation lasted 4 consecutive hours. The isolated essential oil was collected and stored at $4{ }^{\circ} \mathrm{C}$ until analyzed and used (Clevenger type, 1928).

\section{Experimental design:}

Eighty male Albino rats weighing 150-160gm. were obtained from the animal house of the Faculty of Medicine, Alexandria University. Animals were handled in accordance with the principles of laboratory animal care. They were housed in a clean and well ventilated animal house with a constant 12 hours light and 12 hours dark schedule. Clean water ad libitum and pellet diet were given freely. After two weeks of acclimatization, rats were randomly divided into two 5 groups:

Group I (is the control group): Rats received DMSO orally for fourteen consecutive days. Group II (is the coriander volatile oil group): Rats received coriander volatile oil at a dosage of (40 mg/kg B.W. orally) for fourteen consecutive days (Abou El-Soud et al., 2012).

Group III (the Ibuprofen group): Rats were treated orally with Ibuprofen dissolved in $0.9 \%$ saline. Rats received Ibuprofen at a dosage of $100 \mathrm{mg} / \mathrm{kg}$ bodyweight (B.W.), orally for fourteen consecutive days (Garba et al., 2012).Ibuprofen (Brufen @ 600) was purchased from Kahira Pharm. \& Chem. Ind.Co

Group IV (the Ibuprofen+Coriander volatile oil group): Rats received coriander volatile oil at a dosage of $40 \mathrm{mg} / \mathrm{kg}$ body weight, followed by Ibuprofen at a dosage of $100 \mathrm{mg} / \mathrm{kg} \mathrm{B.W}$ orally for fourteen consecutive days.

Group V(is the Ibuprofen withdrawal group): rats were treated orally with Ibuprofen dissolved in $0.9 \%$ saline solution. The rats received Ibuprofen at a dosage of (100mg/kg B.W. orally) for fourteen consecutive days. Ibuprofen treatment was withdrawn for a period of fourteen days after fourteen days of treatment period .

\section{Biochemical and histological preparation:}

Twenty four hours after the last treatment schedule, the animals were sacrificed by decapitation. For biochemical analysis,the liver was removed and washed in $0.9 \%$ saline solution then stored at $-20^{\circ} \mathrm{C}$. Liver alanine aminotransferase (ALT) and aspartate aminotransferase (AST) activitywas determined using the method ofReitman and Frankel (1975).For histological study, the liver of the different groups were immediately fixed in $10 \%$ formalin saline solution. Paraffin sections $5 \mu \mathrm{m}$ thick were stained with haematoxylin and eosin (Drury and Wallington, 1980).

\section{Statistical analysis:}

Statistical analysis was performed using one way ANOVA, using Statistical Product and Service Solutions (SPSS, 2010) program produced by Statistical Analysis Systems Institute. Significant differences among means were evaluated at $\mathrm{p}<0.05$.

\section{Results \\ Biochemical results:}

The present results presented in Table (1) revealed that a significant $(p<0.05)$ decrease in liver transaminases, in the treatment group, in both groups (group 3 and group 4) treated with IBU when compared with the control group, whereas group 4 which was treated with coriander oil and IBU revealed a significant $(\mathrm{p}<0.05)$ increase in both AST and ALT activities when compared to group 3 which was treated only with IBU, on the other hand, group 2 which was treated only with coriander oil revealed a significant $(p<0.05)$ increase when compared to control group. Liver transaminases activities were found to be significantly $(p<0.05)$ increased in the animals after withdrawn of ibuprofen. 
Table (1): The changes in aspartate aminotransferase (AST), alanine aminotransferase (ALT) activities in liver of male rats treated with ibuprofen (IBU), coriander oil and their combination after treatment and recovery periods.

\begin{tabular}{|c|c|c|c|c|}
\hline \multirow[t]{2}{*}{ Groups } & \multicolumn{2}{|c|}{ Doses administered } & \multicolumn{2}{|c|}{ Parameters measured } \\
\hline & $\begin{array}{l}\text { Ibuprofen } \\
\text { (mg/kg) }\end{array}$ & $\begin{array}{c}\text { Coriander volatile oil } \\
\qquad(\mathrm{mg} / \mathrm{kg})\end{array}$ & $\begin{array}{c}\text { AST } \\
\text { (U/mgprotein) }\end{array}$ & $\begin{array}{c}\text { ALT } \\
\text { (U/mg protein) }\end{array}$ \\
\hline Treament group & & & & \\
\hline I(control ) & $\mathbf{0}$ & $\mathbf{0}$ & $122 \pm 1.24^{\mathbf{b}}$ & $163 \pm 4.59^{b}$ \\
\hline II(Coriander oil) & $\mathbf{0}$ & 40 & $141 \pm 2.55^{\mathrm{a}}$ & $189 \pm 6.12^{\mathrm{a}}$ \\
\hline III(IBU) & 100 & $\mathbf{0}$ & $76.91 \pm 1.72^{d}$ & $102 \pm 2.20^{\mathbf{d}}$ \\
\hline IV(IBU+Coriander) & 100 & 40 & $109 \pm 1.22^{c}$ & $131 \pm 2.40^{c}$ \\
\hline $\mathrm{V}(\mathrm{IBU})$ recovery & $\mathbf{0}$ & $\mathbf{0}$ & $106 \pm 3.39^{c}$ & $134 \pm 2.22^{c}$ \\
\hline
\end{tabular}

Abcd: Mean values within a row not sharing common superscript letters were significantly different, $\mathrm{p}<0.05$.Values are expressed as means \pm S.E. ( $\mathrm{n}=7$ for each group).

\section{Histological observations:}

The histological examinations of the liver sections are indicative of IBU toxicity and indication of possible represented in Figures (1-5). In Figure 1 showed that liver hepatocellular damage that could exert through alterations of the control rats receiving DMSO orally showing normal in liver functions. These findings are in agreement with the hepatocytes, sinusoids and central vein. The hepatocytes previous studies done by Garba et al. (2012) in which were neatly arranged in anastomosing plates with the plasma ASTand ALT activities showed significant sinusoids radiating from the central vein.Animals received increasein the ibuprofen $(100 \mathrm{mg} / \mathrm{kg})$ treated rats.The $40 \mathrm{mg} / \mathrm{kg}$ of coriander volatile oil orally showing normal reduction in transaminases may be due to tissue damage, histological structure of the liver including normal alterations of the permeability of cell membrane (Farage et hepatocytes, sinusoids and central vein (Fig.2). Animals al., 2010). Aprioku et al. (2014) studied the effects of receiving $100 \mathrm{mg} / \mathrm{kg}$ ibuprofen orally showing dilation and ibuprofen (20 and $40 \mathrm{mg} / \mathrm{kg}$ ) on hepatic, renal, and congestion of blood vessel, area of necrosis, and wide hematological indices in relation to dose and duration of spread areas of vacuolar degeneration (Fig.3a,b). Animals treated with $100 \mathrm{mg} / \mathrm{kg}$ ibuprofen $+40 \mathrm{mg} / \mathrm{kg}$ of the coriander volatile oil showed normal architecture including normal hepatocytes, sinusoids, and central vein (Fig.4).Animals with withdraw of ibuprofen still showing congested blood vessels (Fig.5).

\section{Discussion}

The present results declared that AST andALT decreased in liver of IBU-treated rats. The decrease in liver AST and ALT is useful in indicating the existences of liver diseases as this enzyme is present in large quantities in liver, it increased in plasma and decreased in liver when cellular damage or degeneration occurs in this organ (Hassoun and Stohs,1995). The decline of thesehese enzymes is an exposure. They reported that the elevation in serum levels of alanine transaminase (ALT) and alkaline phosphatase (ALP) by ibuprofen in their study was indicative of cellular injury to the liver. Aspartate aminotransferase (AST) was also increased dose- and time-dependently, although not significantly. ALT was affected only after 28 days of exposure of the high dose of ibuprofen $(40 \mathrm{mg} / \mathrm{kg}$ ) used in their study, the effect of ibuprofen on liver function was correlated positively with the dose and duration of exposure.

Histological results revealed that IBU induced several histopathological alterations in liver of rats. Similarly,Senthilkumar et al., (2013) reported that the administration of ibuprofen (500 mg/kg B.W.) produced significant changes in the normal hepatic cells, resulting in 
the formation of centrilobular necrosis, vacuolization, and hepatomegaly.Ibuprofen was commonly known to produce hepatotoxicity, inducing cholestatic hepatitis (Manov et al., 2006). Lowe dose of ibuprofen induces more histopathological lesions in rats' liver than chlorpromazine, paracetamol and other (Schoonen et al., 2007). Ibuprofen was reported to cause changes in the architecture of the hepatic cell, cell permeability and to create ionic imbalance resulting in increased intracellular calcium concentration. Consequently, mitochondrial activity was inhibited, leading to the death of hepatic cells (Saraf et al., 1994).Hepatic necrosis induced by ibuprofen is usually associated with elevated levels of liver marker enzymes which is due to the cellular leakage and loss of functional integrity of the cell membrane in liver (Reitman and Frankel, 1957).

Treating animals with IBU and coriander oil caused ameliorative effect in IBU-induced hepatotoxicity. Transaminases, hepatic ALT and AST increased with decrease of histopathological changes. These results are similar to the results obtained by Samojlik et al. (2010) who found that $C$. sativum oil had protective effect against $\mathrm{CCl} 4$-induced hepatotoxicity. They added that this effect is due to the antioxidant activity of $C$. sativum. The antioxidant effect of C.sativum was reported by some investigators. Chithra and Leelamma, (1999)confirmed activation of antioxidant enzymes (catalase, glutathione peroxidase) in rats treated by Coriandrum sativum. Abou El-Soud et al. (2012) reported that the reduced level of the enzyme glutathione peroxidase as a result of induction of diabetes was significantly elevated above the normal control level $(\mathrm{p}<0.05)$ after treatment with coriander oil.

Sriti et al. (2011) demonstrated that the chemical class characters of $C$. sativum EOs from different fruit samples

\section{References}

Abo-El-Soud, N.H., (2010). Herbal medicine in ancient Egypt. J. Medicinal Plants Research, 4(2): 082-086. Abou El-Soud, H. N., El-Lithy, A. N., El-Saeed, M. S. G., Wahby, S. M., Khalil, M. Y., Abou El-Kassem,T. L.; Morsy, F. and Shaffie, N. (2012). Efficacy of Coriandrum sativum L. essential oil as antidiabetic. J.Applied Sciences Research, 8(7): 3646-3655.

Aprioku, J. S., Nwidu, L. L. Amadi, C. N. (2014). Evaluation of toxicological profile of ibuprofen in Wistar albino rats.Am. J. Biomed. Sci. 6(1): 32- 40.

Chithra, V. and Leelamma, S. (1999). Coriandrum sativum changes the levels of lipid peroxides and activity of antioxidant enzymes in experimental animals. Indian J.Biochemistry and Biophysics, 36: 59-61.

Castell, J. V.; Larrauri, A.,Gómez-Lechón, M. J. (1988). A study of the relative hepatotoxicity in vitro of the non-steroidal anti-inflammatory drugs ibuprofen, flurbiprofen and butibufen.Xenobiotica, 18: 737-745.

Chen, H., Jacobs, E., Schwarzschild, M., McCullough, M., Calle, E.,Thun, M., Ascherio, A. (2005).Non-steroidal anti-inflammatory drug use and the risk for Parkinson's disease. Ann Neurol., 58 (6): 963. were monoterpene hydrocarbons ranged between $16.2 \%$ to $20.7 \%$, monoterpene alcohols ranged between $59.4 \%$ to $73.8 \%$, monoterpene esters ranged between $3.7 \%$ to $9.1 \%$, aldehydes ranged between $0.3 \%$ to $0.9 \%$, ketones ranged between $3 \%$ to $6.5 \%$; and phenols about $0.06 \%$ ). The raw coriander contained mainly of linalool (72.7\%) followed by l-terpinene (8.8\%), a-pinene (5.5\%), camphor (3.7\%), limonene $(2.3 \%)$, geranyl acetate $(1.9 \%)$ and p-cymene (1.5\%) (Mageed et al., 2012).Coriander (Coriandrum sativum L.) volatile oil is rich in beneficial phytonutrients andhave been qualified as natural antioxidants. The main components of the essential oil are camphor (44.99\%), cyclohexanol acetate (cis-2-tert.butyl-) (14.45\%), limonene (7.17\%) and $\alpha$-pinene (6.37\%). Darughe et al. (2012) showed that coriander essential oil at percentage of 0.05 , 0.10 and 0.15 was very much effective in inhabiting primary and secondary oxidation products. It was found that at the proportion of $0.02 \%$, its effects were almost equal to BHA (butylatedhydroxylanisole). Shahwar et al. (2012) showed that the coriander seed essential oil had significant radical scavenging activity in comparison with coriander leaf essential oil. Sriti et al. (2011) reported that the methanolic extracts of coriander fruits showed better antioxidant activity than EOs and the 2,2 - diphenyl -1picrylhydrazyl (DPPH).Radical scavenging activity scavenging ability of methanolic extracts of coriander fruits was higher than that of synthetic antioxidant butylatedhydroxy toluene (BHT) which IC50 equal 25 $\mathrm{mg} / \mathrm{ml}$ ). It is concluded from the present work coriander volatile oil treatment minimized and alleviated the hazardous effects IBU and this may be attributed to the vital role of coriander oil active ingredients as antioxidant.

Deepa, B. and Anuradha, C.V. (2011). Anti-oxidant potential of Coriandrium sativum L. seed extract. Ind. J. Exp. Biol., 49: 30-38

Darughe.F.; Barzegar, M., Sahari, M. A. (2012).Antioxidant and antifungal activity of Coriander (Coriandrum sativum L.) essential oil in cake. Int. Food Res. J., 19(3): 1253-1260.

Drury, R. V. A. and Wallington, E. A. (1980). Carlton's histological techniques. 5thed, Oxford University Press: New York, Pronto.

Emamghoreishi, M., Khasaki, M.,Aazam, M. F. (2005).Coriandrum sativum: Evaluation of its anxiolytic effect in the elevated plus-maze.J. Ethnopharmacology, 96: 365-370.

Farage, A. G. A., Elhalwagy, M. E. A., Farid, H. E. A. (2010). Effect of ginger supplementation on developmental toxicity induced by fenitrothion insecticide and/or lead in albino rats. Pest Biochem Phzysiol; 97: 267274.

Garba, A. M.; Mohammed, B.; Garba, S. H.; Numan, A. I.; Dalori, B. M. (2012). The effects of honey and Aloe vera extract on ibuprofen induced liver damage in rats. IOSR-JPBS, 3(2): 2278-3008. 


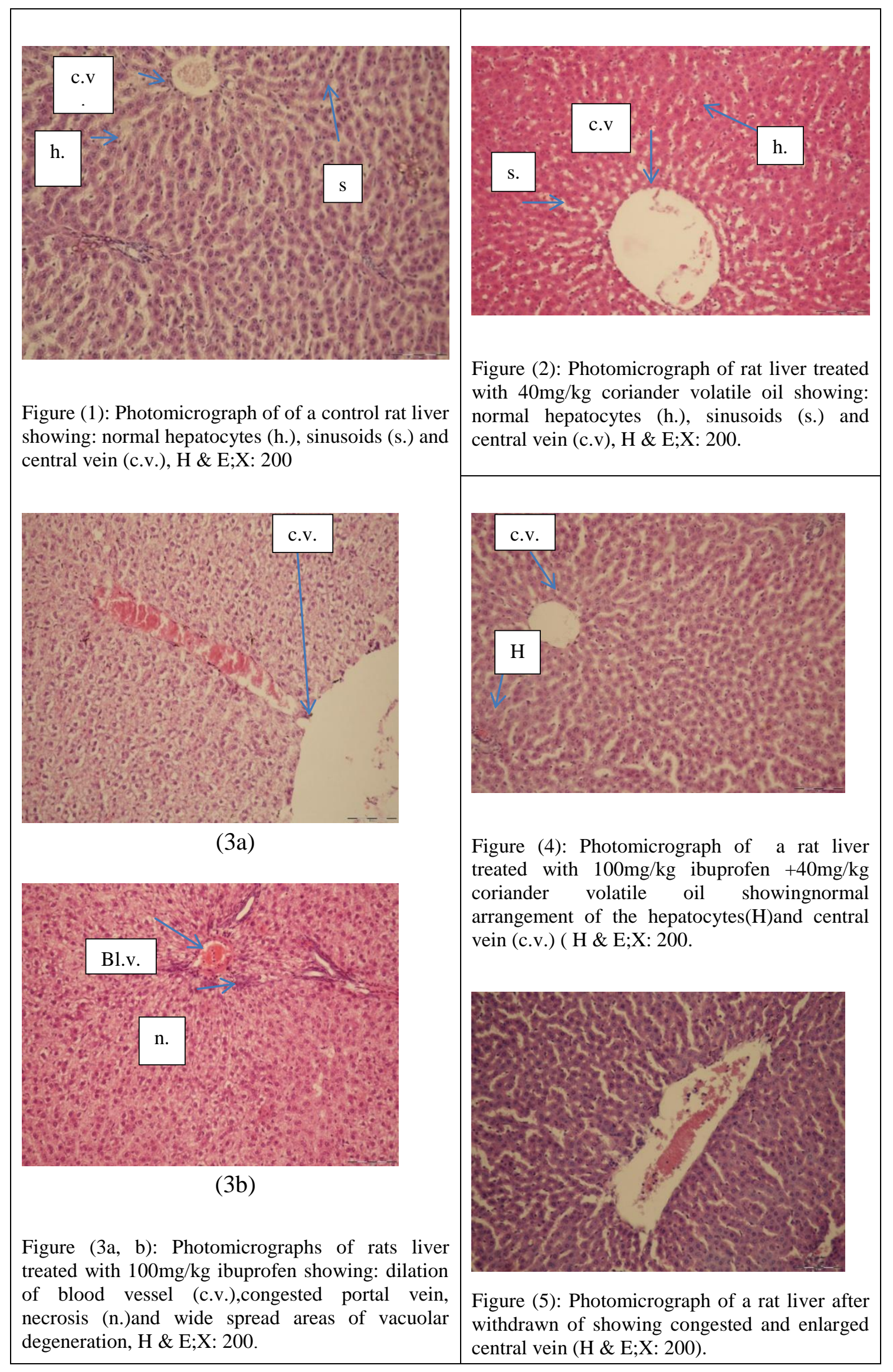


Hassoun, E. A.,Stohs, S. J. (1995).Comparative studies on oxidative stress as a mechanism for the fetotoxicity of TCDD, endrin and lindane in C57BL/6J and DBA/2J mice.Teratol., 51: 186.

Li, S.Z., Ben C. M. (1999). Chinese Archives Publishing House, Beijing.

Mageed, M.A.A.E, Mansour, A.F., Massry, K.F.E., Ramadan, M., Shaheen, M.S.; Shaaban, H. (2012).Effect of microwaves on essential oils ofcoriander and cumin seeds and on their antioxidant and antimicrobial activities. J.Essent Oil Bear Plants, 15: 614-27

Mahalakshmi, R., Rajesh, P., Ramesh, N., Balasubramanian, V., Rajesh Kannan, V. (2010).Hepatoprotective activity on Vitexnegundo Linn. (Verbenaceae) by using Wistar Albino Rats in Ibuprofen induced model. International J. Pharmacology, 6(5): 658663.

Manov, I., Motanis, H., Frumin, I., Iancu, T. (2006). Hepatotoxicity of anti-inflammatory and analgesic drugs: ultrastructural aspects. Acta Pharmacol.Sin., 27: 259-272.

Momin, A. H., Acharya, S. S., Gajjar, A. V. (2012).Coriandrum sativum- review of advances in phytopharmacology. IJPSR, 3: 1233-1239.

Neffati, M., Sriti, J., Hamdaoui, G., Kchouk, M. E.,Marzouk, B. (2011). Salinity impact on fruit yield, essential oil composition and antioxidant activities of Coriandrum sativum fruit extracts. Food Chemistry, 124: 221-225.

Reitman, S. and Frankel, S. (1957).Colorimetric method for the determination of serum glutamic oxalacetic and glutamic pyruvic transaminases. Am. J. Clin. Pathol., 28(1): 56-63.

Ringman, J. M., Frautschy, S. A., Cole, G. M., Masterman, D. L., Cummings, J. L. (2005). Potential role of the curry spice curcumin in Alzheimer's disease. Curr. Alzheimer Res., 2: 131-136.

Sriti, J., Wannes, W. A., Talou, T., Vilarem, G., Marzouk, B. (2011).Chemical composition and antioxidant activities of Tunisian and Canadian coriander (Coriandrum sativum L.) fruit. J. Essent. Oil Res., 23: 7-15.

Shahwar, M. K., El-Ghorab, A. H., Anjum, F. M., Butt, M. S., Hussain, S., Nadeem, M. (2012).Characterization of Coriander (Coriandrum sativum L.) Fruits and Leaves: Volatile and nonvolatile Extracts. International J. Food Properties, 15: 736-747 .

Samojlik, I., Lakić, N., Mimica-Dukić, N., Đaković-Švajcer, K., and Božin, B. (2010). Antioxidant and hepatoprotective potential of essential oils of coriander (Coriandrum sativum L.) and caraway (Carumcarvi L.)(Apiaceae). J. Agric. Food Chem., 58 (15):8848-8853

Saraf, S., Dixit, V. K.,Tripathi, S. C., Patnaik, G. K. (1994).Antihepatotoxic activity of Cassia occidentalis. International J. Pharmacognosy, 32(2): 38-183.

Schoonen, W. G., Kloks, C. P., Ploemen, J. P., Smit, M. J., Zandberg, P., Horbach, G. J., Mellema, J. R., Thijssen-Vanzuylen, C., Tas, A. C.,van Nesselrooij, J. H., Vogels, J. T. (2007). Uniform procedure of (1) H NMR analysis of rat urine and toxicometabonomics Part II: comparison of NMR profiles for classification of hepatotoxicity. Toxicol. Sci., 98: 286-297.

Senthilkumar, B., Jayavelu, A., Natarajan, A., Sundaresan, S., Devi, K. (2013). Hepatoprotective activity of Boerhavia Diffusa Linn. (Nyctaginaceae) against Ibuprofen induced hepatotoxicity in Wistar albino rats. International J. Pharma Research and Review, 2(4): 1-8.

Teoh, N. C. and Farrell, G. C. (2003). Hepatotoxicity associated with non-steroidal anti-inflammatory drugs, Clin. Liver Dis., : 401-413.

Thangapandian, K. (2012). Ibuprofen Induced Nephrotoxicity in Adult Albino Rats. IJALS, 1: 58-67.

Zoubiri, S. and Baaliouamer, A. (2010). Essential oil composition of Coriandrumsativumfruit cultivated in Algeria as food grains protectant. Food Chem., 122: 12261228. 